\section{Efthymios Constantinides} studied Economics at the BA level and Economics of European Integration at the post-graduate level; his PhD dissertation focused on Marketing in Virtual Environments. After a corporate career of ten years (among others for Ericsson and KLM), he worked as Senior Lecturer Marketing for the International Agricultural College Larenstein, the Netherlands. Currently, he is working as Assistant Professor E-Commerce in the faculty of Management and Governance of the University of Twente, the Netherlands, and is visiting professor at the University of Castilla-La Mancha, Spain. His research interests are focused on strategy in virtual marketplaces, E-Marketing and online consumer behaviour

Stefan J. Fountain

studied Business Information Technology in the Netherlands at the Faculty of Computer Science, University of Twente. He recently completed his MSc thesis, which deals with the effects of Trust and Network effects on the success of online organisations. He is currently working as project leader for the Web 2.0 startup Soocial (www.soocial.com) and is the co-founder of Eight Media web development studio in Arnhem, the Netherlands.

Keywords: Web 2.0, social media, internet marketing, online marketing, online consumer behaviour, direct marketing, marketing strategy

Efthymios Constantinides Faculty of Management and Governance

University of Twente

P.O. Box 217

Enschede $7500 \mathrm{AE}$

The Netherlands

Tel: + 31534893799

Fax: +31534892159

E-mail: e.constantinides@utwente.nl

\section{Special Issue Papers}

\section{Web 2.0: Conceptual foundations and marketing issues}

\author{
Efthymios Constantinides and Stefan J. Fountain \\ Received: 24 October 2007
}

\begin{abstract}
This paper identifies the technological and commercial foundations of the new category of online applications commonly described as Web 2.0 or Social Media. It examines the relevance of Web 2.0 for Marketing Strategy and for Direct Marketing in particular. The issue is not a clear-cut one: while several observers saw in Web 2.0 a new stage in the evolution of the internet, others simply rejected it as a new High-Tech hype while there is still no generally accepted definition and demarcation of the term. Paradoxically, even without an accepted definition and despite lack of extensive research, the corporate world seems to embrace the Web 2.0 concept: high-profile mergers and acquisitions have already taken place or are under way while corporations are rushing to integrate various forms of social media into their marketing planning. The experience so far, based to a large degree on anecdotal evidence, is that Web 2.0 has a substantial effect on consumer behaviour and has contributed to an unprecedented customer empowerment. The consequences are far reaching, affecting not only the area of technology development but also the domains of business strategy and marketing. From the academic but also the practical point of view, attention must be placed on the demarcation and evaluation of the new technologies and trends so that the real value of Web 2.0 as a component of the modern marketing can be determined.

Journal of Direct, Data and Digital Marketing Practice (2008) 9, 231-244. doi:10.1057/palgrave.dddmp.4350098
\end{abstract}

\section{Introduction}

On the 2nd of April 2005, The Economist published an article titled 'Crowned at last' and TIME magazine, breaking a tradition of almost 40 years, assigned the title of the 2006 Man of the Year not to any particular personality but to the modern virtual consumer. The underlying theme of both publications - and many others that followed - was the effect of the new kind of internet applications on shaping a new class of consumers increasingly integrating the web into 
Web 2.0

\section{Web 2.0 is a controversial subject}

their daily life. Both articles describe how the phenomenon commonly referred to as Web 2.0 or Social Media is affecting the way people communicate, make decisions, socialise, learn, entertain themselves, interact with each other or even do their shopping. They also suggest that the Web 2.0, next to transforming peoples' individual and group behaviour, has also affected the power structures in the marketplace, causing a substantial migration of market power from producers or vendors towards customers. The main reason for this is that today's online consumer has access to a previously unknown reservoir of information and knowledge as well as unlimited choice, available at the click of the computer mouse.

The terms Social Media and Web 2.0 are often used as interchangeable; however, some observers associate the term Web 2.0 mainly with online applications and the term Social Media with the social aspects of Web 2.0 applications (participation, openness, conversation, community, connectedness; SpannerWorks, 2007). In this paper, we will use the term Web 2.0 as an umbrella term of web applications fulfilling a number of criteria to be defined further on.

The growing importance of the Web 2.0 and the effects on consumers and organisations are issues frequently making headlines and increasingly attracting academic attention. The interest is often focused on the ways in which these applications contribute to customer behavioural change and on new challenges facing strategists and marketers (Urban, 2003; McKinsey Quarterly, 2007). There is little clarity as to the exact nature of Web 2.0; for all intents and purposes, there is still no generally accepted definition of the term and no systematic research on its importance and its effects on the marketing practice. This paper will attempt to define this phenomenon and identify its dimensions in an effort to help marketers understand the potential of Web 2.0 as a (direct) marketing tool.

\section{What is Web 2.0?}

The term Web 2.0 is around since 2005 but the subject is already controversial. Considerable controversy stems from the fact that Web 2.0 applications are by and large based on content generated by users often being anonymous and lacking qualitative credentials. This is a basic difference from previous internet applications: the user as an essential contributor is a new marketing parameter instigating a migration of market power from producers to consumers and from traditional mass media to new personalised ones.

Controversy is also evident in the lack of general consensus as to what exactly the Web 2.0 is; this paper will apply the following definition when referring to Web 2.0:

Web 2.0 is a collection of open-source, interactive and usercontrolled online applications expanding the experiences, knowledge and market power of the users as participants in business and social processes. Web 2.0 applications support the creation of informal users' networks facilitating the flow of ideas and knowledge by allowing the 


\section{Five main categories}

efficient generation, dissemination, sharing and editing/refining of informational content.

Web 2.0 presents businesses with new challenges but also new opportunities for getting and staying in touch with their markets, learning about the needs and opinions of their customers as well as interacting with them in a direct and personalised way.

A number of technology principles that will be briefly explained in the next chapters are common to Web 2.0 applications. As to the categories of Web 2.0, we propose a basic classification based on application types divided into five main categories:

1. Blogs: Short for Web logs: online journals, the most known and fastest-growing category of Web 2.0 applications. Blogs are often combined with Podcasts, that is, digital audio or video that can be streamed or downloaded to portable devices. Examples: http://gizmodo.com, http://www.boingboing.net, http://www. huffingtonpost.com

2. Social networks: applications allowing users to build personal websites accessible to other users for exchange of personal content and communication. Examples: http://www.myspace.com, http:// www.facebook.com, www.hyves.nl, http://www.ning.com/

3. (Content) Communities: Websites organising and sharing particular types of content. Examples are applications of Video sharing: http:// video.google.com, www.youtube.com, http://etsylove.ning.com, Photos sharing: http://www.flickr.com, Social Bookmarking www. digg.com, http://del.icio.us and publicly edited Encyclopedias www. wikipedia.org, http://en.citizendium.org/wiki/Main_Page

4. Forums/bulleting boards: sites for exchanging ideas and information usually around special interests Examples: www.epinions.com, www.personaldemocracy.com, http://www.python.org.

5. Content aggregators: applications allowing users to fully customise the web content they wish to access. These sites make use of a technique known as Real Simple Syndication or Rich Site Summary (RSS). Examples http://uk.my.yahoo.com/, http://www. google.com/ig, http://www.netvibes.com/

The user is a vital factor for all categories of Web 2.0 applications, not only as a consumer but mainly as a content contributor. The term User-Generated Content (UGC) is often used to underline this special attribute of all the above Web 2.0 application categories.

\section{Evolution and trends of the internet: From Web 1. 0 to Web 2.0}

The recent high-profile takeovers of the internet telephone service Skype and the online payment system PayPal by the successful online auction Ebay, the takeover of the photo-sharing site Flickr by Yahoo and the 1.6-bn-dollar takeover of the still-unprofitable — video exchange site YouTube by Google have placed the subject of Web 2.0 in the spotlight. Some observers already draw parallels to the internet 


\section{Ambiguity}

\section{Main principles}

gold rush of the 1990s. The issue is already a subject of public debate while studies about of the phenomenon have begun to surface (McKinsey, 2007; Forrester, 2007). In the academic literature, the topics of Web 2.0 and social media are slowly attracting attention (Karger and Quan, 2005; Biever, 2006; Deshpande and Jadad, 2006; Boll, 2007) and yet there is no visible line on research interests and no definition of Web 2.0 enjoying general academic acceptance.

The term Web 2.0 was proposed by O'Reilly (2005) and it has quickly become the new buzzword of Silicon Valley circles and the media. For the software industry, the phenomenon is not really new but marketers becoming familiar with Web 2.0 are increasingly engaging this concept as part of their marketing strategy (McKinsey, 2007; Hitwise, ${ }^{1}$ Forrester, 2007). Expectations are high, despite the fact that generally speaking the adoption rate among traditional businesses is still low and the instruments being used are selective and limited. ${ }^{2}$

The term Web 2.0 is used extensively despite the ambiguity as to its exact meaning. Yet, using a common term serves a useful purpose: it helps establish a common vision and provides a platform for development of online service-oriented and customer-controlled applications.

The influence of the Web 2.0 concept is evident in the field. One of the most noticeable trends in the internet-mediated online marketplace is that applications are increasingly being built no more on proprietary platforms but rather on frameworks usually based on open-source software. These frameworks enable the rapid development of new forms of functionality, allowing the 'democratisation' of technology and in many cases even facilitating connectivity to competitive applications. Interconnectivity has substantially increased cooperation and interaction among web users.

The value and benefits underpinning this trend are not always clear and their effects have not yet been studied in a systematic way. One of the reasons for this is the newness but most importantly the complexity of the issue: in the Web 2.0 domain various technical and business aspects are heavily interrelated, often making the identification of the underlying value models difficult.

With regard to the innovative nature of Web 2.0, it can be argued that the movement has not contributed many radically new technological components; it has merely created new families of online applications sharing a number of common sets of objectives, characteristics and design principles. The main innovative aspect of these applications is the way they allow user participation in the form of content contribution and content editing; as such, they are usually built on a common set of development practices and present users with a new value proposition based on network effects.

\section{The Web 2.0 main principles}

As mentioned earlier, Web 2.0 applications must be seen as a new stage in the evolution of the networked world, namely as a new generation of 
online applications sharing a number of common traits. Various authors (Daconta et al., 2003; Shirkey, 2003; Anderson, 2004; O'Reilly, 2005) have identified and analysed these issues as crucial elements of Web 2.0 applications.

The key innovative elements typifying this new family of web applications can be summarised as three main principles. These principles are:

1. Focus on service-based, simple and open-source solutions in the form of online applications.

2. Continuous and incremental application development requiring the participation and interaction of users in new ways: not only 'consuming' but also contributing, reviewing and editing content.

3. New service-based business models and new opportunities for reaching small individual customers with low-volume products.

\section{The Web 2.0. main principles in detail}

\section{Detailed principles}

1. Focus on service-based, simple and open-source solutions in the form of online applications. The three main elements are:

(a) Shift towards online services: from software as product to software as service: Unlike the first generation of internet applications developed around proprietary software products, the new Web 2.0 applications are platform independent, very often making use of open-source software. They are offered as a service rather than as packaged software (O'Reilly, 2005), without scheduled releases, usually free to everyone - no licensing fees are charged - easy to download, share and distribute.

(b) Simplicity: Web 2.0 applications are widely considered as simple and unfussy, at least from the user's perspective. User interfaces are less bloated, applications offer a limited number of features and the value proposition for the user is easily recognisable. In the case of content aggregators like My Yahoo and similar $\mathrm{RSS}^{3}$-based sites, the user is allowed to fully customise the application.

(c) The network effects as the vendor lock-in: The obvious winner in the Web 2.0 movement is the user since he/she is in control of the process. These applications often lack a financial vendor lock-in and since the user can easily exchange or substitute any service for another, it seems that network effects and peer usage are important motives for customer loyalty. For example while switching to a competitor of Skype.com (the market leader in internet-based telephone services) could mean a cheaper option, most Skype users will not migrate to another service if their contacts and peers are also Skype.com users; participants of the social networking site MySpace.com or the online community SecondLife (www.secondlife.com) or the 


\author{
Advantages of \\ customer involvement \\ in application \\ development
}

online photo-exchange service Flickr (www.flickr.com) will keep using the service if more and more of their contacts and peers do the same even if there are many other (and even better) options available.

2. Continuous and incremental application development requiring the participation and interaction of users in new ways: not only 'consuming' but also contributing, reviewing and refining content.

The fact that the user can actively participate in the development of Web 2.0 applications offers important benefits to the application owner like immediate access to the voice of the customer and to a very extensive knowledge reservoir. The advantages of customer involvement in application development are:

(a) Continuous, real-time improvement: This is a common practice in many web applications: the photo-exchange service Flickr deploys new builds every half an hour and the internet telephone service Skype frequently asks users for feedback on connection quality after terminating a call, taking action and solving service bottlenecks while customers actually use the service. Proactively using feedback from users is the main differentiating factor between Web 2.0 and older approaches; there is no question of upgrading cycles or software releases but rather a continuous, real-time development, based on actual user feedback and usability controls.

(b) Perpetual beta: The Web 2.0 variant of the Beta version concept is a 'perpetual' beta concept: (O'Reilly, 2005): there is never a definitive version and software remains under development and improvement as long as it exists. Following this concept, the software is commercialised before it is 'feature complete' or free of programming bugs, 'developed in the open, with new features slipstreamed in on a monthly, weekly, or even daily basis' (O'Reilly, 2005).

(c) More users: more value though the aggregation of collective intelligence: Every new user adds value by increasing the size of the collective intelligence pool: the more users participate, the more advanced and valuable the service becomes. Examples of this are applications like the user-generated content tourism site Wikitravel (http://wikitravel.org/en/Main_Page), the online encyclopedias Wikipedia (www.wikipedia.org) and Citizendium (http://en.citizendium.org) and Amazon.com who bases its book recommendations on behavioural profiling and information about the buying preferences of customers with similar profiles.

3. New service-based business models and new opportunities for reaching small individual customers with low-volume products.

(a) Changes in revenue and usage models: A number of Web 2.0 applications secure part of their revenue stream on an online version of the traditional newspaper-like subscription but most offer their services for free, subsidising their operations by advertising revenue or sponsoring (with Google, the most successful search engine service today, as the best-known 
example). A commonly applied form of subscription - the online telephone service Skype being a good example - is to offer a basic service for free and to charge a fee for the premium, more advanced services.

(b) From mass markets to the individual customers: A substantial number of service providers in the Web 2.0 domain seem to understand that next to the high-volume hit products and services, there is a high - previously untapped - market potential of individual, 'unsegmented' consumers with very specific interests and demand for low-volume, customised products and services. Owing to low volumes, such products have so far remained below the radar of the average high-street marketer. Web 2.0 applications like specialised blogs, forums, bulletin boards, podcasts and communities allow consumers to easily learn about the existence of these products and also find them often by simply getting in touch with other consumers sharing the same interests. There is evidence that such niche consumers can create substantial aggregated demand for products and services not belonging to the mainstream or 'hit' categories but to the so-called Long-Tail (Anderson, 2006); Anderson argues that firms able to tap the total sales potential of low-volume products can substantially increase their business; however, concrete scientific evidence of this does not exist yet. ${ }^{4}$ The evidence so far is anecdotal: Some of the most successful Internet businesses seem to already leverage the Long Tail of their markets. Examples include eBay (www.ebay.com) (online auctions), Yahoo! (www.yahoo.com,) .com and Google (www. google.com) (web search), Amazon (www.amazon.com) (retail) and iTunes http://www.apple.com/itunes (music and podcasts), Audible http://www.audible.com (audio books) and Netflix (http://www.netflix.com) (video rental).

\section{Web 2.0 and marketing}

\section{The Web 2.0 and marketing: What is changing?}

The Web 2.0 is a new step in the evolution process of the internet as marketing environment. While some observers reject the Web 2.0 notion as nothing more than another technology fad, its success and wide public acceptance point to the fact that Web 2.0 is here to stay. Several studies suggest that young consumers have already adopted the online social media as an integral part of their life: according to a recent survey by Alloy Media \& Marketing, 96 per cent of US teens go online to participate in a social network at least once a week (Biz Report.com, 27 June 2007).

Next to the young consumers, there is evidence that practitioners are becoming increasingly attracted by the Web 2.0 realm: more than 50 per cent of professionals participate already in social networks according to the Social Network Practitioner Consensus Survey of May 2007 (BizReport.com, 5 June 2007). On the other hand, the mainstream online consumer has noticed that Web 2.0 applications offer new and 


\section{Scepticism \\ surrounding Web 2.0}

previously unknown possibilities and empowerment not only in the form of information sourcing but also as forums of dialogue and confrontation of producers and vendors with their social, ethical and commercial responsibilities. The power of these media can be very substantial and there are already several cases of 'citizen journalism' exposing product failures or corporate misconduct and forcing companies to respond. Some highly publicised cases include the recall of a Dell laptop model and the Kryptonite bicycle lock after blogs exposed serious shortcomings of these products, and American On Line (AOL), which was forced to abolish its high-pressure tactics to prevent customers from giving up their subscriptions. All these cases started with a blog posting that reached millions of users and ultimately reached the wider public through the traditional media.

Despite the positive perspectives there is still scepticism surrounding Web 2.0: Keen (2007), Keegan (2007) and Wilson (2007) argue that the Web 2.0 and specifically applications based on user-generated content present a real and present danger to the established culture. Some of the arguments: anonymous amateur videos and music remixes posted to sites like YouTube, Google Video and other such sites contribute to public frustration (the viewer is not able to distinguish between reality, fiction and advertising) and abuse of intellectual rights (from using copyrighted material like music, video, logos, etc), leading to the demise of professional artists and the entertainment industry in general. Next to this, the complete lack of control and accountability allows everyone to become a self-proclaimed expert and influence those who are not able to distinguish between quality and nonsense. Gillin (2007) and others, on the other hand, argue that in fact the social media represents a healthy phenomenon, becoming the new source of consumer creativity, influence and empowerment. An interesting consequence of customer empowerment is that traditional media and old-style marketing are constantly losing ground as influencers of consumer behaviour. According to the 2004 Yankelovick Monitor, ${ }^{5} 60$ per cent of US consumers have a much more negative picture about Marketing and 70 per cent of consumers tune out advertising much more often than a few years ago. Consumers do not trust traditional marketers as they used to: a recent study of Deloitte Touche USA reveals that 62 per cent of the US consumers read consumergenerated online reviews and 98 per cent of them find these reviews reliable enough; 80 per cent of these consumers say that reading these reviews has affected their buying intentions (emarketer.com, 12 October 2007).

Despite these negative signals, it is essential for marketers to look to Web 2.0 as a challenge rather than as a threat and consider it as a new domain of commercial strategy. As such, the subject poses some interesting questions: what are the dimensions and the possible consequences of the Web 2.0 phenomenon on the marketing practice? What are the possible responses of business to the phenomenon and which of these responses are likely to be successful? 


\section{Growing demand}

\section{Web 2.0 and marketing}

\section{Main consequences: Shift in market power, value offering and customer needs}

An important effect of the Web 2.0-mediated customer empowerment is a visible shift in consumer attitudes. Some of the symptoms are the surfacing of new customer needs, the emerging new value perceptions and the change of consumer search tactics and buying behaviour.

The shift in customer needs is reflected in the growing demand for online services, particularly in the Web 2.0 domain, where consumers can not only interact with marketers but also access peer communities. The fast expansion of the 'blogsphere' and other online platforms where people can post and exchange personal ideas, videos, pictures and tags but also participate in virtual worlds or games has by now created its own dynamics: it occurs without any form of marketing effort from the part of the application providers. The value attributed to these applications is not based on the classic customer value approach but rather on some feeling of achievement through personal gratification. As to the consumer behaviour this is increasingly influenced by peer opinions and the collective intelligence (Surowiecki, 2005).

\section{Web 2.0 as a direct marketing tool}

What could Web 2.0 mean to marketers and how can they integrate it into the corporate commercial strategy? Recognising the effects of Web 2.0 on the consumer's decision-making process, understanding the sources of customer value and the motives of consumers to use these applications are the first steps to this direction. Web 2.0 applications are becoming increasingly popular due to the advantages they offer to users (transparency, referrals, contacts with other users, etc) and their effect on customer power (Urban, 2003). Interaction with peers triggers new customer needs (often for niche and highly personalised products) and alter buying attitudes. The new buying attitudes are not limited to the online buying behaviour but extend to the traditional one: according to a recent survey of the Sterling Committee 'consumers want a seamless buying experience across all channels' (BizReport, 30 August 2007). Moreover, the customer preferences and experiences about the products and services offered either in traditional or electronic outlets are not based any more exclusively on information made available through traditional mass media or corporate websites. In the Web 2.0, era customer preferences and decisions are increasingly based on inputs provided by parties beyond the control of online marketers: peer reviews, referrals, blogs, tagging, social networks, online forums and other forms of - uncontrollable by the marketer user-generated content.

As a result, the internet, and particularly the Web 2.0 as a new marketplace component, further complicates the time-honoured 'textbook' buying behaviour process described in the Inputs Processing - Response model (Figure 1) where the elements A and B represent the traditional influencers of the consumer behaviour: these are the conventional marketing influences (A) and the uncontrollable personal influencers (B) (Kotler, 2003). 


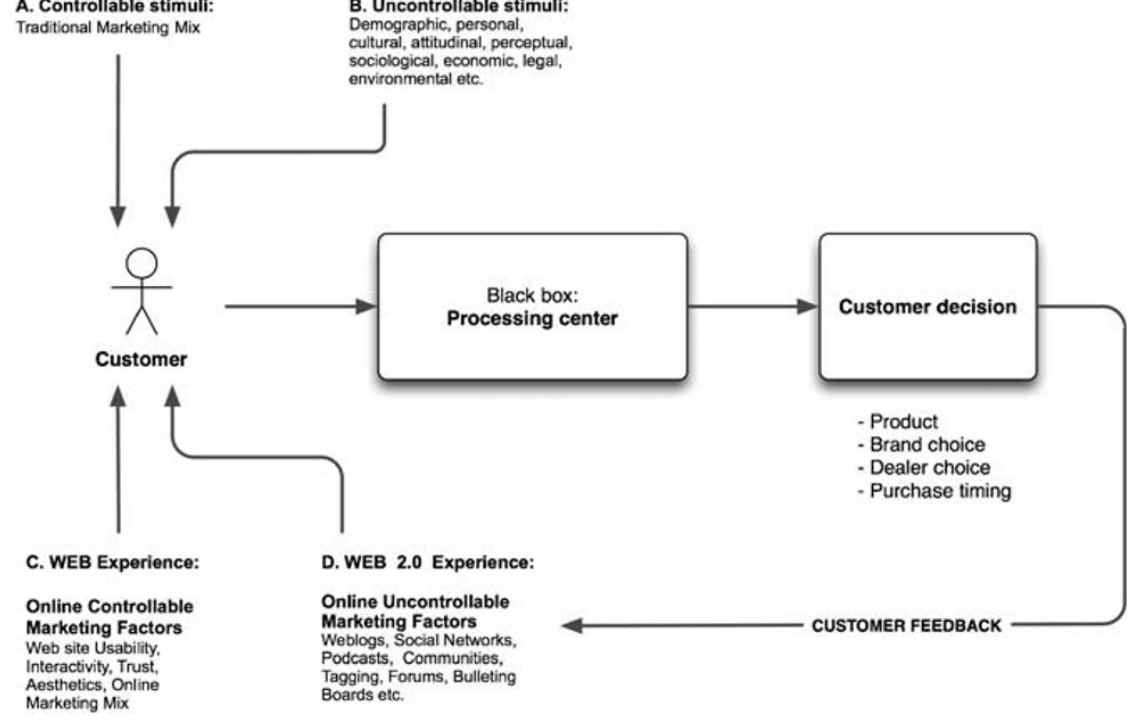

Figure 1: Factors influencing the decision-making process in an information-based marketplace adapted from Kotler (2003) and Constantinides (2004)

Notes: $\mathrm{A}$ and $\mathrm{B}$ : Factors affecting the buying decision-making process in traditional shopping environments. A, B and C: Factors affecting the buying decision-making process in an internet (Web 1.0)-mediated environment. A, B, C and D: Factors affecting the buying decision-making process in an internet (Web 2.0)-mediated environment

\section{Increasing complexity of the customer decision-making process}

In today's digital-focused marketing environment, the internet as a communication and transaction channel adds two more inputs and influencers of buying behaviour to the model: the online marketing mix (C), which basically represents the controllable online experiences provided by the corporate website (Constantinides, 2004), and the Web 2.0 influences (D), which are by and large beyond the marketer's control.

Figure 1 underlines the increasing complexity of the customer decision-making process in the Web 2.0 environment: as the web user and the technology mature, marketers discover that influencing the consumer behaviour by means of traditional marketing media and practices becomes less effective. Next to the new parameters entering the decision process equation, an additional problem is the increasing mistrust of consumers for traditional, mass marketing tactics as explained earlier; these consumer attitudes are reflected on the diminishing effect of mass media. ${ }^{6}$

Identifying ways to enhance user experience, meeting the customer's information needs and helping customers become successful - an approach known as customer advocacy — will be the future keys to success. Even in the case of product categories previously considered as generic (like travel and vacation services), vendors discover that they can gain and retain customers by offering something more than only low prices (Gilden, 2006). There is evidence that customer reviews posted in different forums or online communities, Web blogs and podcasts are much more powerful as marketing tools than expert product reviews (Gillin, 2007); the influence of blogs and podcasts is increasing because of the fast expansion of the audience and contributors. ${ }^{7}$ 


\section{Corporate options}

Firms can capitalise on these developments in three different ways:

- The first way is to understand how social media function and include them in their PR arsenal as a means of reaching and informing the new online opinion leaders (bloggers, podcasters, etc) about their products, services and new market offers; this in an effective means of passing the message through to their target markets or even to very specific market segments at a fraction of the costs required by traditional media. Advertising in well-selected blogs and popular search engines can also be a very interesting and relatively low-cost communication option.

- The second way in which marketers can engage the Web 2.0 is by actively and consequently 'listen-in' to the customer's voice: what people say about the firm and its products in blogs, podcasts, forums and online communities. This is by no means an easy task but there are already tools available to marketers: specialised parties and search engines making possible the detection and collection of this type of online content. The value and quality of this information are obvious. People like to exchange online experiences about products, services and firms, advising others or even proposing how products can be improved; this is high-quality and low-cost market information. A simple way to start is to search for content related to the firm and posted in sites like YouTube. Coca Cola discovered that a rage of amateur videos were building up in YouTube showing the funny experiences of customers dropping Mentos mints into Diet Coke bottles, something that is causing an explosive soda fountain. After initially distancing itself from the exploding Diet Coke videos and several unsuccessful efforts to stop them, the company finally understood the value of this free publicity, signing a formal deal with the initial creators of the videos. Based on this idea, the firm introduced the 'Coca-Cola Challenge' campaign asking consumers to submit videos showcasing creative uses of everyday household items.

- The third way to utilise Web 2.0 media is to engage these as tools of direct, personalised one-to-one marketing. Brick-and-mortar firms like Nike, Disney, Coca Cola, TIME magazine, The Hearst Media, etc are already experimenting with social media as part of their direct marketing strategy seeking communication, interaction and customer feed back. They do this by introducing Web 2.0 web sites based on user-generated content and encouraging social networking and community forming. These sites offer their customer the possibility to reach their peers, exchange information and experiences.

Active participation in the Web 2.0 domain
Another option is to actively participate in the Web 2.0 domain by launching corporate blogs and podcasts. Several business executives like the CEO of Sun Microsystems Jonathan Swartz, the CEO of Apple Computers Steve Jobs and the McDonalds Vice President Bob Langert post regularly on corporate blogs, encouraging customers to interact 


\section{Personalised products}

\section{New stage in the internet's evolution}

and freely express their feelings, suggestions or remarks about the company and its products.

Some firms are going a step further: SONY, Frito-Lay's, Sunkist are some examples of a growing pool of corporations partnering with talented amateurs, who create viral films or television commercials for them. The idea behind such partnerships is that messages created by real customers reflect the genuine feelings of product users and as such they are more credible and more effective than messages created by advertising agencies.

An alternative approach is the increasingly popular corporate practice taking advantage of the rising customer individualism namely providing customers with personalised products. There are several examples of firms offering customers online tools allowing modification, customisation or even the design of company products. Pioneers in this area are companies like Kleenex (myklenextissue.com), a service called photostamps.com allowing consumers to create their own (US Postal Service approved) stamps from their photos, Heinz (myheinz.com) inviting customers to create their own personalised labels of their ketchup bottle and M\&M (nymms.com) allowing customers to select their favourite candy colours and have a personalised message printed on it. Pepsi invites fans to design their soft drink cans in the Design Our Pepsi Can Contest (www.designourpepsican.com), with the best idea adopted as the new look of the product in regular intervals, and NIKE offers similar tools to its customers, allowing customising the sport articles they order online (http://nikeid.nike.com).

\section{Conclusions and issues for further research}

The growing family of Web 2.0 applications appears to be a new stage in the internet's evolution. These applications are suitable for using new forms of interactive, one-to-one marketing. A number of common software development trends and commercial principles underpin the Web 2.0 applications. Furthermore, these applications directly affect the market power structures to the benefit of consumers rather than corporations. These effects require new marketing strategies and approaches.

The Web 2.0 movement emphasises the trend towards openness and technology democratisation and introduces new forms of participation based on decentralisation and user-generated content. They present consumers with a whole array of options in searching for value products and services and finding exactly what they need and want with minimum effort, in line with the current customer desire for personalisation, individual approach and empowerment. By introducing a new uncontrollable element into the customer decision-making process equation, the Web 2.0 domain presents a new challenge to marketing strategists who witness the diminishing effect of traditional marketing practices as customers' influencers. The obvious course for marketers is to engage the new media in passive and active ways as part of the overall marketing strategy: as part of the PR and communication mix, as new channels for listening to the customer's 


\section{Three main topics}

\section{The social media are here to stay}

voice and as means for direct, one-to-one marketing. These areas are already pioneered by corporations testing and adopting new tactics based on openness, dialogue and individual (one-to-one) approach, offering customers the possibility to express their needs, creativity and experiences and in some cases even involving customers in the production of communication messages and the design of their products.

From the academic point of view, these developments present a challenging research domain that should embrace three main topics:

1. The identification and classification of the different types of applications and instruments belonging to the Web 2.0 category from the technological but also from the commercial perspective. This will provide the basis for a comprehensive definition as a basis for the systematic analysis of the phenomenon.

2. The study of the effects of these instruments on consumer perceptions, needs and behaviour and the study of the effects of Web 2.0-based approaches on market niches.

3. The value of Web 2.0 applications as marketing tools and ways to maximise the effectiveness of these tools. The important questions here refer to how these tools can be efficiently incorporated into the marketing strategy, how they can become sources of additional business value and how to use these as effective instruments of customer acquisition and retention.

Finally, all indications point to the fact that the social media are here to stay. In the future, Marketers should learn to co-exist and communicate with a powerful customer very little sensitive to old-fashioned push marketing and by and large determined to participate as an equal in the marketing process.

\section{Notes}

1. HitWise.com, in a study published in April 2007, calculates the participation of Web 2.0 to the top participatory websites to be 12,28 per cent, a 668 per cent increase compared to two years ago.

2. Marketingvox.com, 28 March 2007.

3. RSS stands for Rich Site Summary. This technology allows web users to easily customise and access websites of interest.

4. Anderson focuses on the specific example of online music sales in comparison with music products sold in music stores where only the most popular music is selling enough units justifying shelf space. Less popular music numbers or albums do not sell enough and thus are not taken in the assortment of traditional brick and mortar stores where physical shelf space is limited.

5. 2004 Yankelovich Marketing Resistance Survey.

6. 2004 Yankelovich Monitor

7. According to Technorati.com, a firm measuring the development of this phenomenon as of 30 September 20061.3 million blog posts are published daily, $54.000+$ per hour.

\section{Further reading}

Anderson, C. (2006) 'The long tail: Why the future of business is selling less of more', Hyperion, ISBN 1401302378 


\section{Constantinides and Fountain}

Biever, C. (2006) 'Web 2.0 is all about the feel-good factor', The New Scientist, Vol. 192, pp. 30.

Boll, S. (2007) 'MultiTube - Where Web 2.0 and multimedia could meet', IEEE Multimedia, Vol. 14, No. 1, pp. 9-13.

Constantinides, E. (2004) 'Influencing the online consumer's behaviour: The web experience', Journal of Internet Research, Vol. 14, No. 2, pp. 111-126.

Daconta, M. (2003). The Semantic Web: A Guide to the Future of XML, Web Services, and Knowledge Management, John Wiley \& Sons Inc, New York.

Deshpande, A. and Jadad, A. (2006) 'Web 2.0: Could it help move the health system into the 21st century', The Journal of Men's Health \& Gender, Vol. 3, No. 4, pp. 332-336.

Gilden, J. (2006) 'Travel websites gain visitors by offering more than low prices', Los Angeles Times, 22 January 2006.

Gillin, P. (2007). The New Influencers, A Marketer's Guide to the New Social Media, Quill Driver Books IWord Dancer Press, Inc, CA, USA.

Karger, D. and Quan, D. (2005) 'What would it mean to blog on the semantic web', Web Semantics: Science, Services and Agents, Vol. 3, No. 2-3, pp. 147-157.

Keegan, V. (2007) 'Amateurs can be good and bad news', The Guardian, 5 July 2007.

Keen, A. (2007). The Cult of the Amateur: How Today's Internet is Killing our Culture, Doubleday/ Random House, New York.

Kotler, P. (2003). Marketing Management, 11th edn, Prentice-Hall International Editions, Englewood Cliffs, NJ.

Li, C. and Stromberg, C. (2007). Calculating the ROI of Blogging: A Case Study, A Look At The ROI Of General Motors' FastLane Blog, Forrester Research, http://www.forrester.com/Research/ Document/Excerpt/0,7211,41066,00.html.

McKinsey. (2007) 'How business are using Web 2.0: A McKinsey global survey', The McKinsey Quarterly, http://www.mckinseyquarterly.com/Marketing/How_businesses_are_using_Web_20_ A_McKinsey_Global_Survey_1913_abstract.

O'Reilly, T. (2005) 'What is Web 2.0?', http://www.oreillynet.com/pub/a/oreilly/tim/news/2005/09/ 30/what-is-web-20.html.

Shirkey, C. (2003) 'Power laws, weblogs, and inequality, networks, economics, and culture mailing list', Source: http://www.shirky.com/writings/powerlaw_weblog.html.

SpannerWorks. (2007) 'What is social media', www.spannerworks.com/ebooks.

Surowiecki, J. (2005). The Wisdom of Crowds, Anchor Books, New York.

Urban, G. (2003) 'Customer advocacy: Is it for you? MIT Sloan School of Management', Center for E-Business, Paper 175.

Weill, P. and Vitale, M. (2001). Place to Space, Migrating to e-Business Models, Harvard Business School Press, Boston, MA, USA.

Wilson, A. N. (2007) 'The Internet is destroying the world as we know it', Daily Mail Online, 8 June 2007. 